\title{
Targeting Acyl Homoserine Lactone (AHL) of Pseudomonas aeruginosa Responsible for Biofilm Formation using Plant Metabolites
}

\author{
Sree Samanvitha K. ${ }^{1}$ (D), Sanjay Kumar S. ${ }^{1}$, Antony V. Samrot ${ }^{2 *}$, Raji P. ${ }^{3}$, \\ Ponnaiah Paulraj' ${ }^{2}$, Iyappan P. ${ }^{2}$, Chandramohan M. ${ }^{2}$, Jenifer Selvarani A. ${ }^{3}$ (D) and \\ Durga Sruthi P. ${ }^{3}$ (i)
}

\begin{abstract}
${ }^{1}$ Department of Biotechnology, Shanmugha Arts, Science, Technology \& Research Academy, Thanjavur, India. ${ }^{2}$ Department of Biomedical Sciences, Faculty of Medicine and Biomedical Sciences, MAHSA University, JalanSP2, Bandar Saujana Putra, 42610, Jenjarom, Selangor, Malaysia. ${ }^{3}$ Department of Biotechnology, Sathyabama Institute of Science and Technology, Chennai - 600 119, India.
\end{abstract}

\begin{abstract}
$\mathrm{AHL}$ (acyl homoserine lactone) is a signaling molecule responsible for communication in gram negative bacteria, which is liable for bacterial virulence as well as biofilm formation. This study aims in targeting the AHL formation and AHL mediated virulence factor using plant extracts / plant metabolites. AHL plays a major role in pigment production, motility and rhamnolipid production in Pseudomonas aeruginosa. Inhibition of these mechanism by any mean implies that it is having impact in biofilm formation too. Plant derived metabolites/ extracts were subjected for swarming motility assay, the metabolite which inhibited the swarming motility was subjected for further study, where $P$. aeruginosa SU-3 was allowed to grow in the presence of the metabolite and its impact over the AHL production, pigment production and rhamnolipid production was evaluated. Curcumin was found to be effective against all the metabolites used. Thus curcumin subjected for molecular docking against ENR (enoyl carrier protein reductase), the enzyme involves in fatty acid synthesis and production of AHL.
\end{abstract}

Keywords: Pseudomonas aeruginosa SU-3; acyl homoserine lactone (AHL); rhamnolipid; pyocyanin pigment; enoyl reductase; molecular docking.

*Correspondence: antonysamrot@gmail.com

(Received: 01 July 2019; accepted: 22 August 2019)

Citation: Sree Samanvitha K., Sanjay Kumar S., Antony V. Samrot, Raji P., Ponnaiah Paulraj, Iyappan P., Chandramohan M., Jenifer Selvarani A. and Durga Sruthi P., Targeting Acyl Homoserine Lactone (AHL) of Pseudomonas aeruginosa Responsible for Biofilm Formation using Plant Metabolites, J Pure App/ Microbiol., 2019; 13(3): 1841-1846. https://doi.org/10.22207/JPAM.13.3.61

(c) The Author(s) 2019. Open Access. This article is distributed under the terms of the Creative Commons Attribution 4.0 International License which permits unrestricted use, sharing, distribution, and reproduction in any medium, provided you give appropriate credit to the original author(s) and the source, provide a link to the Creative Commons license, and indicate if changes were made. 


\section{INTRODUCTION}

Biofilm is the gathering of microbes to form a consortium of cells within a polymeric matrix containing an assortment of substances enclosed inside the slimy mould based on the surroundings or surfaces it develops amidst ${ }^{1}$. Costerton $^{2}$ elucidated how wild type bacteria plan their survival strategy through extreme environmental conditions, the wild strains form a substantial substratum around the cells through which the protracted flimsy fimbriae projected aids in precise attachment to inert surfaces. Pseudomonas aeruginosa is dextrous in skillfully subjugating the systemic immunity whenever there is a contingency and forms tenacious biofilms within individuals predominantly suffering from cystic fibrosis ${ }^{3}$. The biofilm formed by Pseudomonas aeruginosa is rich in glycoproteins called alginate, composed of continuous non repetitive units of glucuronic acid and mannuronic acid, imparting a mucoidal appearance ${ }^{3}$ that deteriorates the chances of mitigating cystic fibrosis ${ }^{4,5}$. Biofilm of Pseudomonas aeruginosa, is regulated by a density dependent mechanism coordinated through the presence of specific signalling molecules such as Acyl Homoserine Lactone (AHL), this mechanism is termed as Quorum Sensing (QS) controlled by las and $r h l$ signaling systems $\mathrm{s}^{6}$ mostly by $\mathrm{N}$ ( 3 oxododecanoyl) homoserine lactone (3OC12-HSL) and N-butanoylL-homoserine lactone $(C 4-H S L)^{7,8}$. The various virulence factors associated with Pseudomonas aeruginosa are also influenced depending upon the cell population density of the organism 9 . Cao et $a .^{11}$ explained the role of another definite transcriptional regulator $m v f r$ influencing quorum sensing. The mvfr controls the quinolone signalling in Pseudomonas aeruginosa which regulates various virulence factors such as pyocyanin,

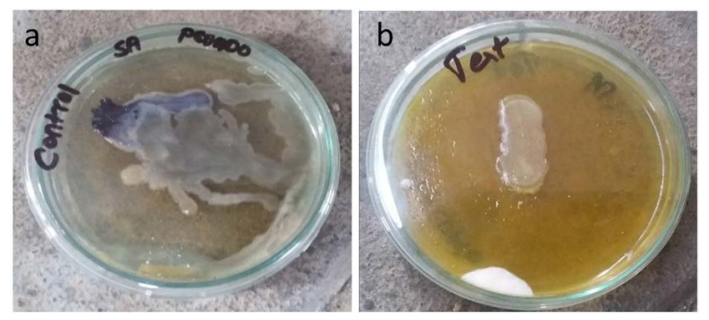

Fig. 1. Swarming motility of Pseudomonas aeruginosa a) Control b) Against curcumin elastase and rhamnolipid ${ }^{10}$. Rhamnolipids are molecules consisting of a hydrophilic carbohydrate unit L-rhamnose and a hydrophobic lipid unit hydroxyalkanoloxy alkanoic acid (HAA) which are linked through a glycosidic bond ${ }^{12}$.

Migration in Pseudomonas aeruginosa is facilitated by monotrichous flagellum through an aqueous medium provided with limited agar source and by the dilation and contraction of pilus in case of solid surfaces ${ }^{13}$. Pseudomonas aeruginosa produces a strikingly noxious blue green pigment that belongs to the phenazine family which competently induces reactive oxygen species ${ }^{14}$ and furthermore involved in the production of 1-hydroxy phenazine and phenazine -1- carboxylic acid other than pyocyanin ${ }^{15}$. According to Dietrich et al. (2006) pyocyanin is a terminal signaling molecule ${ }^{16}$. The biosynthesis of pyocyanin is carried out when LasR and RhIR binds to 30C12-HSL and C4-HSL respectively ${ }^{17}$. Certain naturally occurring substances derived from plant sources are making progress as potential antiquorum sensing compounds ${ }^{18}$. Curcumin is one such natural compound belonging to the Zingiberaceae family having anti-inflammatory, antioxidant, antibacterial, antifungal and very few reports addressing antiquorum sensing properties $^{19}$.

In this study, metabolites extracted from plant and commercially available curcumin were tested against swarming motility of Pseudomonas aeruginosa. The influence of bioactive compounds against the mechanisms regulated by quorum sensing such as the production of AHL, pigment production and rhamnolipid production was also studied along. The effective molecule was studied for its interaction against Enoyl acyl carrier protein reductase (ENR) enzyme responsible for the chain elongation that is involved in the fatty acid synthesis, which is highly responsible for $\mathrm{AHL}$ formation ${ }^{20}$.

\section{MATERIALS AND METHODS Organism chosen}

Pseudomonas aeruginosa SU-1 reported in our earlier study ${ }^{26}$ was used in this study (Genbank Accession number -GU395985).

\section{Various bioactive compounds used}

Alkaloids ${ }^{28}$, flavonoids ${ }^{29}$, saponins ${ }^{27,30}$ and tannins ${ }^{28}$ of Cassia alata, Annona muricata, Mentha 
spicata, Cassia senna, Euphorbia hirta, Thespesia populnea and Wrightia tinctoria were isolated and used in this study .Commercially available curcumin (Merck, India) were used in this study.

\section{Swarming motility test}

$0.5 \%$ agar, $0.5 \%$ peptone and $0.2 \%$ beef extract were taken in $5 \mathrm{~mL}$ distilled water, autoclaved and was mixed with $5 \mathrm{~mL}$ of filter sterilized $1.0 \% \mathrm{w} / \mathrm{v}$ glucose. It was poured onto a sterile petri plate. The extracts/ curcumin with appropriate concentrations were seeded with 5 $\mathrm{mL}$ of $0.5 \%$ agar, melted and poured immediately onto the $10 \mathrm{~mL}$ of pre-poured agar plate as an overlay. $2 \mu \mathrm{L}$ of overnight culture of $P$. aeruginosa was inoculated at the centre of the agar surface and the plates were incubated for $24 \mathrm{~h}$ at $37^{\circ} \mathrm{C}$.
Extraction and Characterization of acyl homoserine lactone (AHL), pyocyanin and rhamnolipid

Pseudomonas aeruginosa inoculated into the $1 \mathrm{~L}$ of nutrient broth containing the effective compound/ extract ( $5 \mathrm{mg}$ ) (which showed effective inhibition of swarming motility alone was used here). Cell supernatants in the stationary phase cultures were extracted with equal two volume of ethyl acetate acidified with $0.5 \%$ acetic acid for three times. The solvent was removed by rotary evaporation $\left(40-45^{\circ} \mathrm{C}\right)$ and the residue was resuspended in $1 \mathrm{~mL}$ of $20 \% \mathrm{ACN}$.

$P$. aeruginosa culture grown as above condition was used for pigment extraction ${ }^{22}$ and for rhamnolipid extraction. Rhamnolipid extract

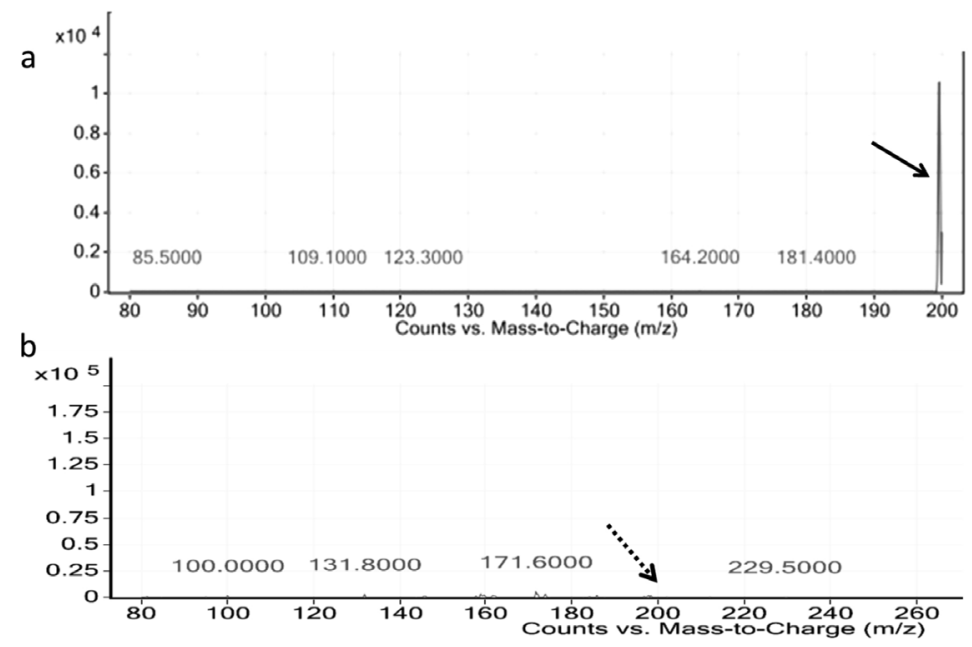

Fig. 2. LC-MS analysis of AHL of Pseudomonas aeruginosa a) Control b) grown with curcumin

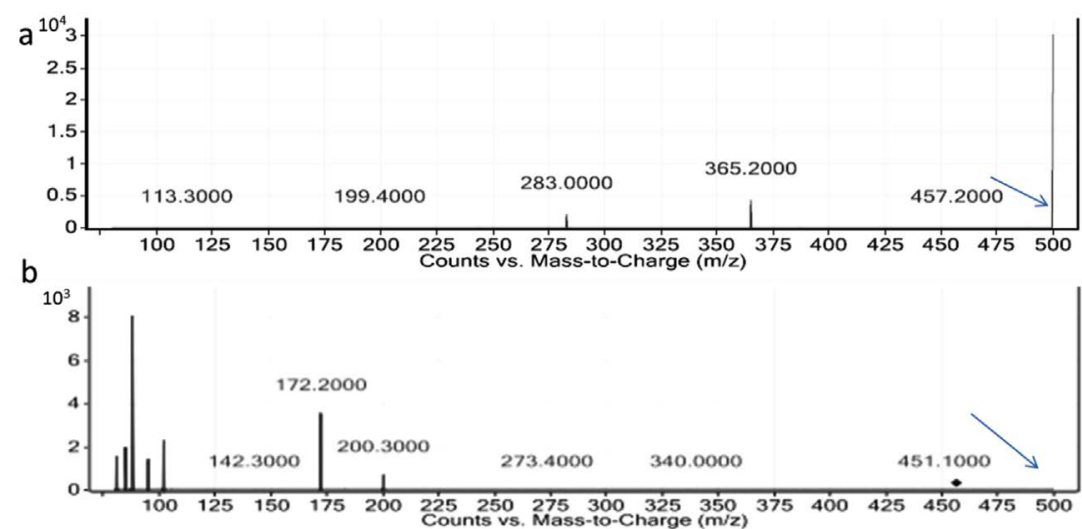

Fig. 3. LC-MS analysis of rhamnolipid of Pseudomonas aeruginosa a) Control b) grown with curcumin 
was done as follows - the overnight culture of Pseudomonas aeruginosa was centrifuged at $10000 \mathrm{rpm}$ for $20 \mathrm{~min}$ at $4^{\circ} \mathrm{C}$ and the supernatant was adjusted to $\mathrm{pH} 2.0$ by addition of $6 \mathrm{M} \mathrm{HCl}$. The solution was centrifuged at $10000 \mathrm{rpm}$ for $20 \mathrm{~min}$ at $4^{\circ} \mathrm{C}$. Precipitate bound to the tubes were added with ethyl acetate. Ethyl acetate was allowed to evaporate.

Thus, obtained homoserine lactone, pyocyanin and rhamnolipid were subjected for LC-MS/MS analysis using Agilent 6400 Series Triple Quadra pole. The samples were eluted with an isocratic mobile phase of Acetonitrile: $5 \mathrm{mM}$ Ammonium formate $(70: 30)^{21}$.

\section{Molecular Docking}

Molecular docking was carried out between the receptor molecule enoyl acyl carrier protein reductase enzyme responsible for the chain elongation and this key enzyme involved in the fatty acid synthesis and curcumin using Discovery Studio version 2.1.

\section{RESULTS AND DISCUSSION Swarming motility test}

The swarming motility plates were observed. There was effective inhibition for curcumin (Fig. 1b) but not for other metabolites (results not shown here) which was further taken to comprehend the effect towards the signaling molecule. Various plant extracts and plant derived materials have shown effective inhibition of swarming motility ${ }^{31}$.
Extraction and Characterization of acyl homoserine lactone (AHL), pyocyanin and rhamnolipid

LC-MS analysis of AHL was found to show a strong peak at $\mathrm{m} / \mathrm{z} 200$, where the peak is characteristic of $3-\mathrm{OH}-\mathrm{C} 5$ - HSL (Homoserine lactone $)^{23,24}$ (Fig. 2a), where the characteristic peak of $3-\mathrm{OH}-\mathrm{C} 5-\mathrm{HSL}$ was found missing in curcumin treated cells (Fig. 2b).

LC-MS analysis revealed the presence one major component detected at $\mathrm{m} / \mathrm{z} 499$ corresponding to Rha-C10-C8 (Fig. 3a) ${ }^{25}$, curcumin treatment had a detrimental impact on the rhamnolipid production too (Fig. 3b).

Likewise, curcumin was showing impact on pigment too (Fig. 4b). rhamnolipid and pigments are influenced by AHL only. Inhibition of AHL has impact on virulence factors like rhamnolipid and pigments.

Molecular docking

Docking was performed using Accerlys Discovery studio version 2.1 where the receptor molecule was enoyl acyl carrier protein reductase and the ligand used was curcumin. The hydrogen in the $41^{\text {st }}$ position of curcumin interacts with Aspargine in the $222^{\text {nd }}$ position in the $B$ chain of Enoyl acyl carrier protein reductase and the oxygen in the $3^{\text {rd }}$ position of curcumin interacts with Tryptophan in the $55^{\text {th }}$ position in the $B$ chain of Enoyl acyl carrier protein reductase.

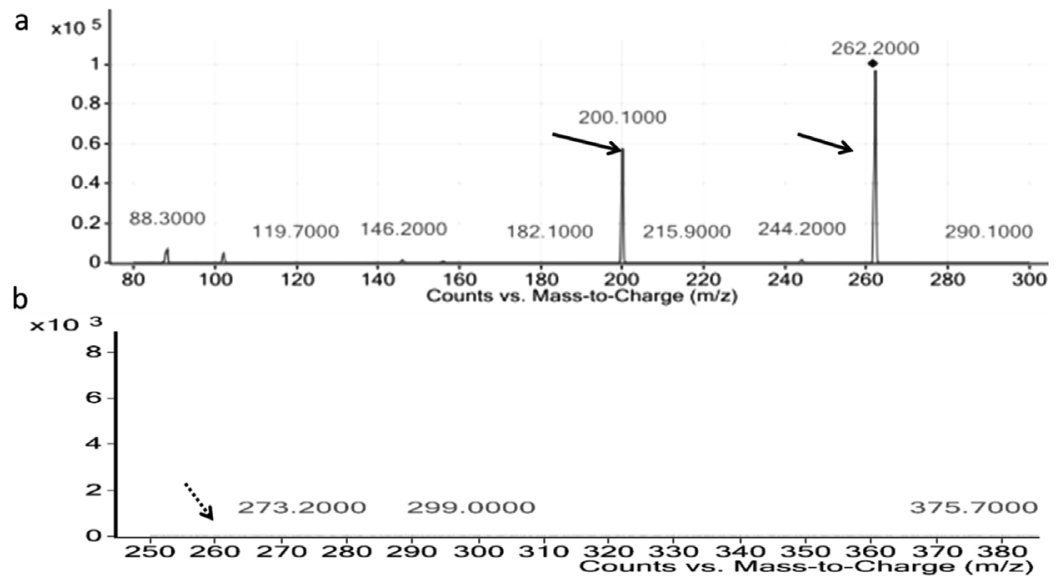

Fig. 4. LC-MS analysis of pyocyanin pigment of Pseudomonas aeruginosa a) Control b) grown with curcumin 

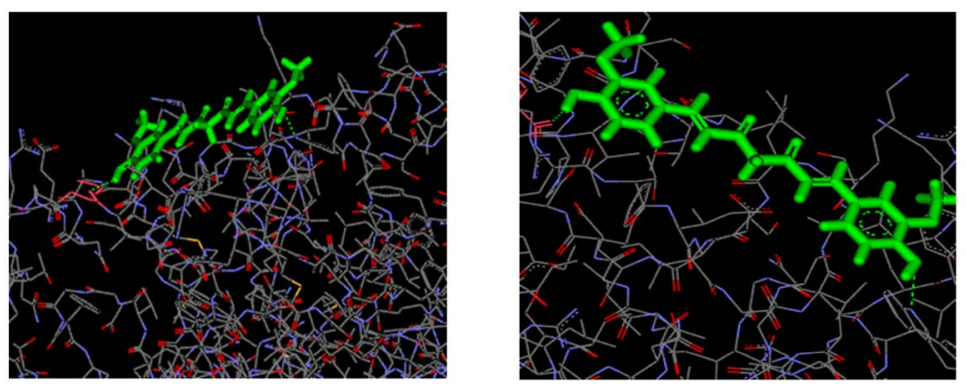

Fig. 5. Molecular docking of curcumin against ENR (enoyl carrier protein reductase)

\section{CONCLUSION}

Curcumin has shown effective inhibition of swarming motility and even showed impact on $\mathrm{AHL}$ production. It also showed negative impact against the quorum sensing molecules like pyocyanin pigment and rhamnolipid. Further, the molecular docking studies revealed that curcumin could interact with enoyl reductase enzyme responsible for AHL formation.

\section{ACKNOWLEDGEMENTS}

None.

\section{CONFLICT OF INTEREST}

The authors declares that there is no conflict of interest.

\section{AUTHORS' CONTRIBUTION}

All the authors involved in idea creation. Ms. Samanvitha did all the work and supported by Mr. Sanjay Kumar. All the authors involved in manuscript preparation.

\section{FUNDING}

None.

\section{DATA AVAILABILITY}

All data generated during the study are included in the manuscript.

\section{ETHICS STATEMENT}

This article does not contain any studies with human participants or animals performed by any of the authors.

\section{REFERENCES}

1. Donlan, R.M. Biofilms: Microbial Life on Surfaces. Emerging Infectious Diseases, 2002; 8(9):
881-890. https://doi.org/10.3201/eid0809.020063.

2. Costerton, J.W.Introduction to biofilm. International J Antimicrob Agents, 1999; 11(3): 217 - 221. https:// doi.org/10.1016/S0924-8579(99)00018-7.

3. Ryder, C., Byrd, M., Wozniak, D.J.Role of polysaccharides in Pseudomonas aeruginosa biofilm development. Curr. Opin. Microbiol., 2007; 10(6): 644-648. https://doi. org/10.1016/j.mib.2007.09.010

4. Govan, J.R., Deretic, V.Microbial pathogenesis in cystic fibrosis: mucoid Pseudomonas aeruginosa and Burkholderiacepacia. Microbiol. Rev., 1996; 60(3): 539-574.

5. Friedman, L., Kolter, R. Two Genetic Loci Produce Distinct Carbohydrate-Rich Structural Components of the Pseudomonas aeruginosa Biofilm Matrix. J. Bacteriol., 2004; 186(14): 4457-4465. https://doi. org/10.1128/JB.186.14.4457-4465.2004.

6. Whitley, M., Lee K.M., Greenberg, E.P. Identification of genes controlled by quorum sensing inPseudomonas aeruginosa.Proc. Natl. Acad. Sci. USA., 1999; 96(24):13904-13909. https://doi.org/10.1073/ pnas.96.24.13904

7. Dekimpe, V. \& Deziel, E. Revisiting the quorumsensing hierarchy in Pseudomonas aeruginosa: the transcriptional regulator RhIR regulates LasRspecific factors. Microbiology, 2009; 155(3): 712-723. https:// doi.org/10.1099/mic.0.022764-0.

8. Singh, P.K., Schaefer, A.L.,Parsek, M.R., Moninger, T.O., Welsh, M.J., Greenberg, E.P. Quorum-sensing signals indicate that cystic fibrosis lungs are infected with bacterial biofilms. Nature, 2000; 407: 762-764. https:// doi.org/10.1038/35037627

9. Kiratisin, P., Tucker, K.D., Passador, L.LasR, a Transcriptional Activator of Pseudomonas aeruginosa Virulence Genes, Functions as a Multimer. Journal of Bacteriology, 2002; 184(17): 4912-4919. https://doi.org/10.1128/JB.184.17.49124919.2002.

10. D'ziel, E., L'pine, F., Milot, S., Villemur, R. rhlA is required for the production of a novel biosurfactant promoting swarming motility in Pseudomonasaeruginosa: 3-(3-hydroxy-alkanoyloxy) alkanoic acids (HAAs), the precursors of rhamnolipids. Microbiol., 2003; 149(8): 2005-2013. https://doi.org/10.1099/mic.0.26154-0.

11. Cao, H., Krishnan, G., Goumnerov, B., Tsongalis, J., Tompkins, R., Rahme, L.G.A quorum sensingassociated virulence gene of Pseudomonas aeruginosa 
encodes a LysR-like transcription regulator with a unique self-regulatory mechanism. Proc. Natl. Acad. Sci. USA., 2001; 98(25): 14613-14618. https://doi. org/10.1073/pnas.251465298.

12. Jarvis, F. G.\&Johnson, M. J.A glycolipid produced by Pseudomonas aeruginosa. J. Am. Chem. Soc., 1949; 71: 4124-4126. https://doi.org/10.1021/ja01180a073.

13. Kyhler, T., Curty, L.K., Barja, F., van Delden. C., Pech vre. J.C. Swarming of Pseudomonasa-eruginosa Is Dependent on Cell-to-Cell Signaling and Requires Flagella and Pili. J. Bacteriol., 2000; 182(21): 59905996. https://doi.org/10.1128/JB.182.21.59905996.2000.

14. El-Fouly,M.Z., Sharaf,A.M., Shahin, A.A.M., El-Bialy, H.A., Omara, A.M.A. Biosynthesis of pyocyanin pigment by Pseudomonas aeruginosa. Journal of Radiation Research and Applied Sciences, 2015; 8(1): 36-48. https://doi.org/10.1016/j.jrras.2014.10.007.

15. Denning, G. M., Iyer, S.S., Reszka, K.J., O'Malley, Y., Rasmussen, G.T., Britigan, B.E.Phenazine-1-carboxylic acid, a secondary metabolite of Pseudomonas aeruginosa, alters expression of immunomodulatory proteins by human airway epithelial cells. Am. J. Physiol. Lung Cell Mol. Physiol., 2003; 285: L584-L592. https://doi.org/10.1152/ajplung.00086.2003.

16. Dietrich, L.E.P., Price-Wheelan, A., Petersen, A., Whiteley, M., Newman, D.K.The phenazine-pyocyanin is a terminal signalling factor in the quorum sensing network of Pseudomonas aeruginosa.J. Mol Microbiol., 2016; 61(5): 1308-1321. https://doi.org/10.1111/ j.1365-2958.2006.05306.x.

17. Lau, G.W., Hassett, D.J., Ran, H., Kong, F. The role of pyocyanin in Pseudomonas aeruginosa infection. Trends Mol. Med., 2004; 10(12): 599-606. https://doi. org/10.1016/j.molmed.2004.10.002.

18. Musthafa, K.S., Ravi, A.V., Annapoorani, A., Packiavathy, I.S.V., Pandian, S.K. Evaluation of anti-quorumsensing activity of edible plants and fruits through inhibition of the $\mathrm{N}$-acyl-homoserine lactone system in Chromobacteriumviolaceum and Pseudomonas aeruginosa. Chemotherapy, 2010; 56: 333-339. https://doi.org/10.1159/000320185.

19. Rudrappa, T. \& Bais, H. P.Curcumin, a known phenolic from Curcuma longa, attenuates the virulence of Pseudomonas aeruginosa PAO1 in whole plant and animal pathogenicity models. Journal of Agricultural and Food Chemistry, 2008; 56: 1955-1962. https://doi. org/10.1021/jf072591j.

20. Huang, Y.H., Lin, J.S., Ma, J.C., Wang, H.H. Functional Characterization of Triclosan-Resistant Enoyl-acyl-carrier Protein Reductase (FabV) in Pseudomonasaeruginosa. Front Microbiol., 2016; 7: 1903. https://doi.org/10.3389/fmicb.2016.01903.

21. Wang, J., Quan, C., Wang,X., Zhao,P., Fan, S.Extraction, purification and identification of bacterial signal molecules based on $\mathrm{N}$ acyl homoserine lactones. Microb. Biotechnol., 2011; 4: 479-490. https://doi. org/10.1111/j.1751-7915.2010.00197.x.
22. Essar, D.W., Eberly, L., Hadero, A., Crawford, I.P. Identification and characterization of genes for a second anthranilate synthase in Pseudomonasaeruginosa: interchangeability of the two anthranilate synthases and evolutionary implications. J. Bacteriol., 1990; 172: 884-900. https://doi.org/10.1128/ jb.172.2.884-900.1990.

23. Ransome, E., Munn, C.B., Halliday,N., Cבmara, M., Tait,K.Diverse profiles of $\mathrm{N}$-acyl-homoserine lactone molecules found in cnidarians. FEMS Microbiol. Ecol., 2014, 87: 315-329. https://doi.org/10.1111/15746941.12226.

24. Samrot, A.V., Azeemullah, S.A., Sujitha, R., Azharudeen, S.M., Samanvitha, S.K., Sneha, S.J. Characterization of Acyl Homoserine Lactone of pigment producing Pseudomonas aeruginosa SU-3. Der Pharma Chemica., 2016; 8(9): 74-79.

25. Loftabad, T.B., Abassi, H., Ahmadkhaniha, R., Roostaaza, R., Masoomi, F., Zahiri, H.S., Ahmadian, G., Vali, H., Noghabi, K.A. Structural characterization of a rhamnolipid-type biosurfactant produced by Pseudomonas aeruginosa MR01: Enhancement of di-rhamnolipid proportion using gamma irradiation. Colloids and Surfaces B: Biointerfaces, 2010; 81(2): 397405. https://doi.org/10.1016/j.colsurfb.2010.06.026. 26. Senthilkumar, P., Dawn, S.S., Samanvitha, S.K., Kumar, S.S., Kumar, G.N., Samrot, A.V.Optimization and characterization of poly[R] hydroxyalkanoate of Pseudomonas aeruginosa SU-1 to utilize in nanoparticle synthesis for curcumin delivery. Biocatalysis and Agricultural Biotechnology, 2017; 12: 292 - 298. https://doi.org/10.1016/j.bcab.2017.10.019.

27. Obadoni, B.O.\& Ochuko, P.O.Phytochemical studies and comparative efficacy of the crude extracts of some haemostatic plants in Edo and Delta States of Nigeria. Global Journal of Pure and Applied Sciences, 2002; 8: 203-208. https://doi.org/10.4314/gjpas.v8i2.16033.

28. Harborne, A.J. In: Phytochemical methods a guide to modern techniques of plant analysis. $3^{\text {rd }}$ Ed. Chapman \& Hall, UK, 1998.

29. Zeidan, S., Hijazi, A., Rammal, H., Kobaissi, A., Badran, B.Extraction of phenolic compounds and flavonoids from Eryngium creticum I. by conventional and nonconventional extraction techniques. World Journal of Pharmacy and Pharmaceutical Sciences, 2014; 3(17): 1889-1898.

30. Ujowundu, F.N., Ukoha, A.I., Ojiako, A.O., Nwaoguikpe, R.N. Isolation of bioactive phytochemicals in leaves of Combretum dolichopentalum and their hydrogen peroxide scavenging potentials. Pharm Anal Acta., 2015; 6: 444. https://doi.org/10.4172/21532435.1000444.

31. Samrot, A.V., Raji, P., Selvarani, A.J., Nishanthini, P. Antibacterial activity of some edible fruits and its green synthesized silver nanoparticles against uropathogenPseudomonas aeruginosa SU 18. Biocatalysis and Agricultural Biotechnology, 2018; 16: 253-270. https:// doi.org/10.1016/j.bcab.2018.08.014. 